\title{
Subject Disease Milestones Supplemental Qualifiers Dataset
}

National Cancer Institute

\section{Source}

National Cancer Institute. Subject Disease Milestones Supplemental Qualifiers Dataset. NCl Thesaurus. Code C147249.

A dataset containing supplemental information, specifically non-standard variables, to parent records in the subject disease milestones domain. 